\title{
SISTEMAS DE MANEJO E RELAÇÕES HÍDRICAS DO SOLO NA PRODUTIVIDADE DA CULTURA DA SOJA, EM PONTA GROSSA - PARANÁ ${ }^{1}$
}

\section{SOIL MANAGEMENT SYSTEMS AND WATER RELATIONS ON THE SOYBEAN CROP PRODUCTIVITY, IN THE REGION OF PONTA GROSSA, STATE OF PARANA, BRAZIL}

\author{
Marla Alessandra ARAUJO ${ }^{2}$ \\ Jorge Luiz Moretti de SOUZA ${ }^{3}$ \\ Gilvano Ebling BRONDANI ${ }^{4}$ \\ Volnei PAULETTI ${ }^{5}$
}

\section{RESUMO}

O presente trabalho teve como objetivo estimar a influência de quatro sistemas de manejo e relações hídricas do solo sobre a produtividade da cultura da soja, cultivada em um Latossolo Vermelho Distrófico típico, na região de Ponta Grossa - PR. Os dados de produtividade da cultura da soja (11 safras) e climáticos necessários nas análises foram disponibilizados pela Fundação ABC e SIMEPAR, respectivamente. Os sistemas de manejo não diferiram significativamente em relação às produtividades. Contudo, devido à ocorrência de deficiência hídrica nos estádios fenológicos mais críticos, as safras 1998/99, 2001/02 e 2004/05 produziram $347,5 \mathrm{~kg} \mathrm{ha}^{-1}, 462,0 \mathrm{~kg} \mathrm{ha}^{-1}$ e $358,3 \mathrm{~kg} \mathrm{ha}^{-1}$ menos, respectivamente, que a produtividade média. A produtividade da soja, em anos consecutivos do ciclo de rotação de culturas, apresentou redução média 10,31\% nas segundas safras em comparação com as primeiras.

Palavras-chave: Glycine max; rotação de culturas; balanço hídrico.

\begin{abstract}
This study aimed to evaluate the influence of four management systems and soil water relations on the soybean crop productivity. The soil is a Typic Hapludox and it is located in Ponta Grossa region, State of Parana, Brazil. Soybean crop productivity ( 11 crop seasons) and climate data were made available by ABC Foundation and SIMEPAR, respectively. The management systems did not differ significantly in relation to the productivity. However, because of the water deficit occurrence in the most critical phenological stages, the crop seasons 1998/99, 2001/02 and 2004/05 produced $347.5 \mathrm{~kg} \mathrm{ha}^{-1}$, $462.0 \mathrm{~kg} \mathrm{ha}^{-1}$ and $358.3 \mathrm{~kg} \mathrm{ha}^{-1}$ less than the medium productivity, respectively. The soybean crop productivity of consecutive years, in the crops rotation cycle, presented $10.31 \%$ of reduction medium in the second crop seasons compared to the first ones.
\end{abstract}

Key-words: Glycine max; crops rotation; water balance.

\footnotetext{
${ }_{2}^{1}$ Parte da dissertação de mestrado realizada pela primeira autora

${ }^{2}$ Pós-Graduação em Ciências do Solo/Departamento de Solos e Engenharia Agrícola/Setor de Ciências Agrárias/Universidade Federal do Paraná, bolsista do CNPq. Curitiba, PR, Brasil.e-mail: marla.agro@bol.com.br

${ }^{3}$ Engenheiro Agrícola, Doutor em Irrigação e Drenagem, Professor do Departamento de Solos e Engenharia Agrícola (DSEA), Setor de Ciências Agrárias (SCA), Universidade Federal do Paraná (UFPR). Rua dos Funcionários, 1540. Cep 80035-050, Curitiba, PR, Brasil. e-mail: jmoretti@ufpr.br *Autor para correspondência

${ }^{4}$ Pós-Graduação em Recursos Florestais/Escola Superior de Agricultura "Luiz de Queiroz"/Universidade de São Paulo.Piracicaba, SP, Brasil. e-mail: gebrondani@yahoo.com.br

${ }^{5}$ Engenheiro Agrônomo, Doutor em Agronomia, Professor do Departamento de Solos e Engenharia Agrícola/Setor de Ciências Agrárias/ Universidade Federal do Paraná.Curitiba, PR, Brasil e-mail: vpauletti@ufpr.br
} 
ARAUJO, M.A. et al. Sistemas de manejo e relações hídricas do solo...

\section{INTRODUÇÃO}

A cultura da soja (Glycine max (L.) Merrill) apresenta alta capacidade produtiva e um incomensurável papel como fonte de riqueza de forma direta e indireta ao longo de sua cadeia de produção. A soja ocupa o topo do ranking das principais culturas no Estado do Paraná, com destaque para a região de Ponta Grossa, onde a produção de soja equivaleu a aproximadamente $12,5 \%$ da produção estadual na safra normal de 2007/08, registrando uma produtividade média de $3250 \mathrm{~kg} \mathrm{ha}^{-1}$ (SEAB, 2008).

Os sistemas de manejo visam manter o solo em condições ótimas para a germinação, emergência das plântulas, desenvolvimento e produtividade das culturas (Veiga \& Amado, 1994), diferenciando-se basicamente pela forma e intensidade do preparo realizado no solo. Desta forma, os sistemas de manejo do solo interferem em muitos de seus atributos, tais como: conteúdo de matéria orgânica, atividade microbiana, disponibilidade de nutrientes, capacidade de troca de cátions, $\mathrm{pH}$, massa específica, capacidade de infiltração, condutividade hidráulica, estabilidade de agregados e conteúdo de água disponível (Veiga \& Amado, 1994; Calegari et al., 2006; Llanillo et al., 2006). Cabe ressaltar que o armazenamento de água no solo é um componente do ciclo hidrológico que influencia diretamente a quantidade de água disponível para as culturas agrícolas, o que por sua vez afeta o seu desenvolvimento, crescimento, rendimento e a necessidade de irrigação (Streck \& Alberto, 2006).

Estresses abióticos, como secas, podem além de reduzir significativamente rendimentos em lavouras, restringir latitudes onde espécies comercialmente importantes podem ser cultivadas. O déficit hídrico, geralmente, é o principal fator responsável por perdas na lavoura (Farias et al., 2001). Sob este foco, a cultura da soja é altamente exigente quanto ao suprimento adequado de suas necessidades fisiológicas, sendo que a ocorrência de déficit hídrico ou carência nutricional, de acordo com o estádio de seu desenvolvimento, pode comprometer diretamente a produção final.

A necessidade total de água na cultura da soja, para obtenção do máximo rendimento, varia entre 450 a $800 \mathrm{~mm}$ ciclo $^{-1}$, dependendo das condições climáticas, do manejo da cultura e da duração do ciclo. A disponibilidade de água para cultura é importante principalmente nas fases compreendidas entre a germinação e emergência, e entre a floração e o enchimento de grãos (EMBRAPA, 2006). A ocorrência de deficiência hídrica nesses estádios pode acarretar em perdas significativas na produtividade, por envolverem de forma direta a formação dos componentes primários do rendimento da cultura, que compreendem: número de plantas por área, legumes por planta, grãos por legume e peso médio de grãos
(Mundstock \& Thomas, 2005). Desta forma, verificase que é importante a caracterização da capacidade de água disponível no solo (CAD), para cada tipo de sistema de cultivo, e a avaliação das relações hídricas envolvendo o ciclo da cultura da soja em uma região ao longo do tempo.

O presente estudo teve por objetivo estimar a influência de quatro sistemas de manejo e relações hídricas do solo sobre a produtividade da cultura da soja, na região de Ponta Grossa, Estado do Paraná.

\section{MATERIAL E MÉTODOS}

Os dados de produtividade da cultura da soja foram registrados em um experimento de longa duração em quatro sistemas de manejo do solo (PD - plantio direto; PC - plantio convencional; PM preparo mínimo; PDE - plantio direto com uma escarificação do solo a $0,3 \mathrm{~m}$ de profundidade a cada três anos), conduzido na Estação Experimental da Fundação $A B C$, situada no município de Ponta Grossa - Paraná, Brasil, entre os anos de 1989 a 2007, totalizando 11 ciclos produtivos de soja devido ao esquema de rotação de culturas (Tabela 1). O local possui um Latossolo Vermelho Distrófico típico, textura argilosa, relevo suave ondulado. Maiores detalhes sobre a sucessão cultural e fertilização química utilizada na área experimental (culturas de inverno e verão) no período entre 1993 e 2004 pode ser encontrada em Pavei (2005).

A fim de comparar as médias das produtividades entre os sistemas de manejo estudados, realizou-se a análise estatística (ANOVA) considerando o delineamento inteiramente casualizado, sendo o tratamento constituído pelos sistemas de manejo PD, PC, PM e $\mathrm{PDE}$, considerando 11 repetições (safras) para cada tratamento. Esta análise foi realizada com o auxílio do programa estatístico SOC (EMBRAPA, 1990).

Os valores diários das componentes do balanço hídrico foram estimados com o auxílio do programa "MORETTI - Módulo: Balanço hídrico seqüencial (Periodicidade: 1, 5, 7, 10, 15 e 30 dias), Versão 1.0" (Souza, 2008), desenvolvido baseandose na metodologia de Thornthwaite \& Mather (1955), porém, contendo uma série de adaptações e opções. As análises foram realizadas para uma periodicidade diária e, conforme recomendação de Souza \& Gomes (2008), a opção "equação cosenoidal" foi utilizada para o cálculo do armazenamento de água no solo e/ou "negativo acumulado". O programa necessitou também dos seguintes dados para realização das análises de balanço hídrico para cada safra: precipitação pluvial $(P)$, evapotranspiração de referência (ETo), coeficiente de cultivo $(k c)$, capacidade de água disponível $(C A D)$ e fração de água disponível no solo para um determinado tipo de cultura $(p)$. 
ARAUJO, M.A. et al. Sistemas de manejo e relações hídricas do solo...

TABELA 1 - Cultivares, semeadura e colheita das 11 safras de soja na Estação Experimental da Fundação ABC, Ponta Grossa-PR, para os quatro sistemas de manejo estudados.

\begin{tabular}{cccc}
\hline Safra & Cultivar & Semeadura & Colheita \\
\hline $1991 / 92$ & BR 16 & $18 / 11 / 91$ & - \\
$1992 / 93$ & BR 16 & $24 / 11 / 92$ & - \\
$1994 / 95$ & BR 16 & $11 / 11 / 94$ & $03 / 04 / 95$ \\
$1995 / 96$ & BR 16 & $22 / 11 / 95$ & $08 / 04 / 96$ \\
$1997 / 98$ & BR 16 & $24 / 10 / 97$ & $19 / 03 / 98$ \\
$1998 / 99$ & BR 16 & $05 / 11 / 98$ & $01 / 04 / 99$ \\
$2000 / 01$ & BRS 133 & $29 / 11 / 00$ & $12 / 04 / 01$ \\
$2001 / 02$ & BRS 133 & $01 / 11 / 01$ & $11 / 04 / 02$ \\
$2003 / 04$ & CD 206 & $06 / 11 / 03$ & $08 / 04 / 04$ \\
$2004 / 05$ & CD 206 & $10 / 11 / 04$ & $06 / 04 / 05$ \\
$2006 / 07$ & CD 206 & $27 / 11 / 06$ & $04 / 04 / 07$ \\
\hline
\end{tabular}

Fonte: Fundação ABC (2007)

Os dados diários de $P$ e demais dados climáticos necessários para a estimativa da ETo, variáveis de entrada no programa balanço hídrico, foram disponibilizados pelo Instituto Meteorológico do Paraná (SIMEPAR), sendo provenientes da: (a) Antiga estação climatológica convencional de Ponta Grossa, que ficava no Parque Estadual de Vila Velha, sob latitude $25^{\circ} 14^{\prime} 17^{\prime \prime} \mathrm{S}$, longitude $50^{\circ} 01^{\prime} 16^{\prime \prime}$ W, altitude $801 \mathrm{~m}$; (b) Estação climatológica automática do Campo demonstrativo e experimental de Ponta Grossa - Fundação $A B C$, sob latitude $25^{\circ} 00^{\prime} 49^{\prime \prime} \mathrm{S}$, longitude $50^{\circ} 09^{\prime} 08^{\prime \prime} \mathrm{W}$, altitude $882 \mathrm{~m}$ e clima Cfb, segundo a classificação de Köppen, responsável pela coleta dos dados climáticos da região a partir de 30 de junho de 2002 . Segundo a classificação de Köppen, o clima da região onde se encontra as duas estações climatológicas é subtropical úmido, com verão fresco, ocorrendo geadas no inverno - $\mathrm{Cfb}$.

A ETo diária da região de Ponta GrossaPR para o período estudado foi estimada a partir do método de Penman-Monteith, empregando uma planilha desenvolvida por Araujo \& Souza (2008), utilizando a parametrização recomendada pela FAO (Allen et al., 1998), cuja equação geral é dada por:

$$
\text { ETo }=\frac{0,408 \cdot \Delta \cdot\left(R_{n}-G\right)+\gamma_{\mathrm{psy}} \cdot \frac{900}{(T+273)} \cdot u_{2} \cdot\left(e_{s}-e_{a}\right)}{\Delta+\gamma_{\mathrm{psy}} \cdot\left(1+0,34 \cdot u_{2}\right)}
$$

Sendo: ETo - evapotranspiração de referência $(\mathrm{mm}$ dia $^{-1}$ ); $\Delta$ - declividade da curva de pressão de vapor da água à temperatura do ar $\left(\mathrm{kPa}{ }^{\circ} \mathrm{C}^{-1}\right) ; R_{n}$ radiação líquida na superfície (MJ m $\left.{ }^{-2} \mathrm{~d}^{-1}\right) ; G$ balanço do fluxo de calor no solo $\left(\mathrm{MJ} \mathrm{m}^{-2} \mathrm{dia}^{-1}\right) ; \gamma_{\mathrm{psy}}$
- constante psicrométrica $\left(\mathrm{kPa} \quad{ }^{\circ} \mathrm{C}^{-1}\right) ; \quad T \quad$ temperatura média do ar $\left({ }^{\circ} \mathrm{C}\right) ; u_{2}$ - velocidade do vento a dois metros de altura $\left(\mathrm{m} \mathrm{s}^{-1}\right) ; e_{s}$ - pressão de saturação de vapor $(\mathrm{kPa}) ; e_{a}$ - pressão atual do vapor $(\mathrm{kPa})$.

Os valores de $k c$ utilizados para transformar a ETo em evapotranspiração da cultura $(E T C)$ são os apresentados por Farias et al. (2001), cujos períodos foram adaptados aos estádios fenológicos propostos por Costa (1996). Como todos os cultivares utilizados no presente estudo possuíam um ciclo médio de 140 dias, os valores de $k c$ foram ajustados para este período (Tabela 2). Nas análises, a profundidade efetiva do sistema radicular $(z)$ da cultura da soja variou ao longo de seu desenvolvimento conforme apresentado por Fietz \& Urchei (2002) (Tabela 2).

Os valores de $C A D$ e água disponível $(A D)$ foram obtidos com as seguintes equações:

$$
\begin{aligned}
& C A D_{i}=0,01 \cdot\left(\theta_{C C}-\theta_{P M P}\right) \cdot z_{i} \\
& A D_{i}=C A D_{i} \cdot p
\end{aligned}
$$

Sendo: $C A D_{i}$ - capacidade de água disponível no solo no i-ésimo estádio fenológico $(\mathrm{mm}) ; \theta_{C C}$ umidade do solo na capacidade de campo com base em volume (\%); $\theta_{P M P}$ - umidade do solo no ponto de murcha permanente com base em volume $(\%) ; z_{i}$ - profundidade efetiva do sistema radicular no $i$-ésimo estádio fenológico $(\mathrm{mm}) ; A D_{i}$ - água disponível no solo no i-ésimo estádio fenológico $(\mathrm{mm}) ; p$ - fração de água disponível no solo (adimensional) - sendo considerado igual a 0,5 para a cultura da soja seguindo as recomendações da FAO (Allen et al., 1998). 
ARAUJO, M.A. et al. Sistemas de manejo e relações hídricas do solo...

TABELA 2 - Duração dos estádios fenológicos dos cultivares da cultura da soja e seus respectivos valores de kc e $z$, sugeridos por Costa (1996), Farias et al. (2001) e Fietz \& Urchei (2002), respectivamente.

\begin{tabular}{lccc}
\hline $\begin{array}{c}\text { Estádios } \\
\text { fenológicos }\end{array}$ & $\begin{array}{c}\text { Ciclo de 140 dias } \\
\text { (dias) }\end{array}$ & $\begin{array}{c}k c \\
\text { (adimensional) }\end{array}$ & $\begin{array}{c}\text { Profundidade efetiva das } \\
\text { raízes- } z(\mathrm{~mm})\end{array}$ \\
\hline S-V1/V2 & 15 & 0,56 & 150 \\
V2-R1 & 45 & 1,21 & 300 \\
R1-R6/R7 & 50 & 1,50 & 400 \\
R7-R9 & 30 & 0,90 & 400 \\
\hline
\end{tabular}

S: semeadura; V1: folhas primárias desenvolvidas; V2: folha trifoliada desenvolvida no nó acima das folhas primárias; R1: início da floração; R6: grãos com $3 \mathrm{~mm}$ num dos quatro últimos nós do caule com folha desenvolvida; R7: legume contendo, ao menos, um grão verde que ocupa toda a sua cavidade, em um dos quatro últimos nós do caule com folha desenvolvida; R9: $95 \%$ dos legumes atingiram a cor de legume maduro do referido cultivar (Costa, 1996).

As amostras de solo foram coletadas na área experimental no mês de outubro de 2007 antes do início do plantio de verão. As análises foram realizadas no Laboratório de Física do Solo/ SCA/UFPR, utilizando as metodologias descritas por EMBRAPA (1997): anel volumétrico, para obtenção da massa específica do solo $\left(\rho_{s}\right)$; mesa de tensão, para obter um ponto da curva de retenção da água no solo $\left(\theta_{s u}\right)$ a $6 \mathrm{kPa}$; e, densímetro, para granulometria.

A partir da obtenção experimental do $\theta_{s u}$ (20 $\mathrm{cm}$ de profundidade) e média da $\rho_{s}$ e granulometria para o perfil de 0 a $40 \mathrm{~cm}$, nas 12 parcelas experimentais (três blocos e quatro sistemas de plantio) os dados foram inseridos no programa SPLINTEX versão 1.0 (Prevedello, 1999). Foi adotado o valor de $2,65 \mathrm{~g} \mathrm{~cm}^{-3}$ para massa específica de partícula $\left(\rho_{p}\right)$. O programa retornou as estimativas da umidade de saturação $\left(\theta_{s}\right)$ e residual $\left(\theta_{r}\right)$ com base em volume, bem como dos parâmetros de ajuste da curva de retenção de água no solo $(\alpha, n$ e $m)$ do modelo de Van Genunchten (1980).

$\mathrm{Na}$ Tabela 3 encontram-se os valores médios para a profundidade entre 0 e $40 \mathrm{~cm}$ obtidos na análise granulométrica (areia, silte e argila), $\rho_{s}$, $\theta_{C C}$ e $\theta_{P M P}$. O cálculo da $\theta_{C C}$ e $\theta_{P M P}$ com o modelo de Van Genunchten (1980) foi realizado considerando uma altura da coluna de água $(h)$ de $10 \mathrm{kPa}$ e 1500 $\mathrm{kPa}$, respectivamente.

TABELA 3 - Valores médios dos atributos físicos do solo, na profundidade de 0-40 $\mathrm{cm}$, para cada sistema de manejo adotado no experimento da Fundação ABC, Ponta Grossa-PR.

\begin{tabular}{|c|c|c|c|c|c|c|c|}
\hline \multirow{3}{*}{ Manejo } & \multirow{3}{*}{ Bloco } & \multicolumn{6}{|c|}{ Atributos físicos do solo } \\
\hline & & Areia & Silte & Argila & $\rho_{s}^{*}$ & $\theta_{C C}{ }^{*}$ & $\theta_{P M P^{*}}$ \\
\hline & & \multicolumn{3}{|c|}{----------- dag kg } & $\mathrm{g} \mathrm{cm}^{-3}$ & \multicolumn{2}{|c|}{-------- \% --------- } \\
\hline \multirow{3}{*}{ Plantio Direto } & I & 33,6 & 35,0 & 31,4 & 1,16 & 35,04 & 19,04 \\
\hline & II & 36,8 & 27,7 & 35,4 & 1,02 & 38,95 & 22,74 \\
\hline & III & 34,8 & 31,9 & 33,3 & 1,04 & 40,46 & 21,45 \\
\hline \multirow{3}{*}{$\begin{array}{c}\text { Plantio } \\
\text { Convencional }\end{array}$} & I & 32,9 & 37,1 & 30,0 & 1,15 & 35,61 & 18,50 \\
\hline & ॥ & 33,2 & 35,5 & 31,3 & 1,03 & 36,94 & 20,65 \\
\hline & III & 34,8 & 35,8 & 29,4 & 1,06 & 35,34 & 19,16 \\
\hline \multirow{3}{*}{$\begin{array}{l}\text { Preparo } \\
\text { Mínimo }\end{array}$} & I & 34,0 & 36,0 & 30,0 & 1,18 & 36,77 & 18,01 \\
\hline & II & 33,0 & 30,8 & 36,3 & 1,10 & 33,48 & 22,30 \\
\hline & III & 35,7 & 32,7 & 31,7 & 1,04 & 35,57 & 20,53 \\
\hline \multirow{3}{*}{$\begin{array}{l}\text { Plantio Direto } \\
\text { Escarificado }\end{array}$} & $I$ & 33,8 & 32,0 & 34,2 & 1,14 & 34,27 & 20,62 \\
\hline & II & 32,4 & 34,7 & 32,9 & 1,11 & 34,25 & 20,56 \\
\hline & III & 40,4 & 28,8 & 30,8 & 0,96 & 35,81 & 20,67 \\
\hline
\end{tabular}

${ }^{*} \rho_{S}$ - massa específica do solo; $\theta_{C C}{ }^{*}$ - umidade do solo na capacidade de campo com base em volume; $\theta_{P M P}$ - umidade do solo no ponto de murcha permanente com base em volume.

A análise estatística (ANOVA) para a variável $C A D$ foi realizada em delineamento blocos ao acaso, sendo que o sistema de manejo (PD, PC, $\mathrm{PM}$ e PDE) constituíram as parcelas. O delineamento experimental contou com três blocos e 16 parcelas por bloco, o que totalizou 48 unidades experimentais. Estas análises foram realizadas com o auxílio do programa estatístico SOC (EMBRAPA, 1990).

Após a realização dos balanços hídricos diários das 11 safras analisadas, a avaliação da penalização da produtividade devido à ocorrência de deficiência hídrica foi realizada empregando um índice de satisfação das necessidades de água 
(ISNA), definido como a relação entre a evapotranspiração real $(E R)$ e a evapotranspiração da cultura $(E T C)$, para a cultura da soja (Farias et al., 2001). A estimativa deste índice parte de níveis de risco hídrico, possuindo três classes, as quais dependem da relação ER/ETc obtida nos estádios fenológicos mais críticos ao déficit hídrico (estádios I e III). Desta forma, têm-se ISNA: (a) bom: ER/ETc $\geq 0,65$; (b) regular: $0,55<E R / E T c<0,65$; e, (c) insufuciente: $E R / E T c \leq 0,55$.

Para evitar erros quanto à estimativa do armazenamento de água no solo (ARM) no momento do plantio da cultura da soja, os balanços hídricos realizados para as 11 safras analisadas foram iniciados no mês de junho. Nas simulações envolvendo as 11 safras não houve constatação de variabilidade do $A R M$ no momento do plantio até mesmo quando o $A R M$ foi considerado igual à zero no início do mês de junho de uma determinada safra.

\section{RESULTADOS E DISCUSSÃO}

A Figura 1 apresenta as médias das produtividades alcançadas nos quatro sistemas de manejo adotados na Estação Experimental da Fundação ABC. É possível observar que as produtividades obtidas estiveram, em média, próximas à produtividade média da região de Ponta Grossa, a qual foi de $3250 \mathrm{~kg} \mathrm{ha}^{-1}$ (Seab, 2008).

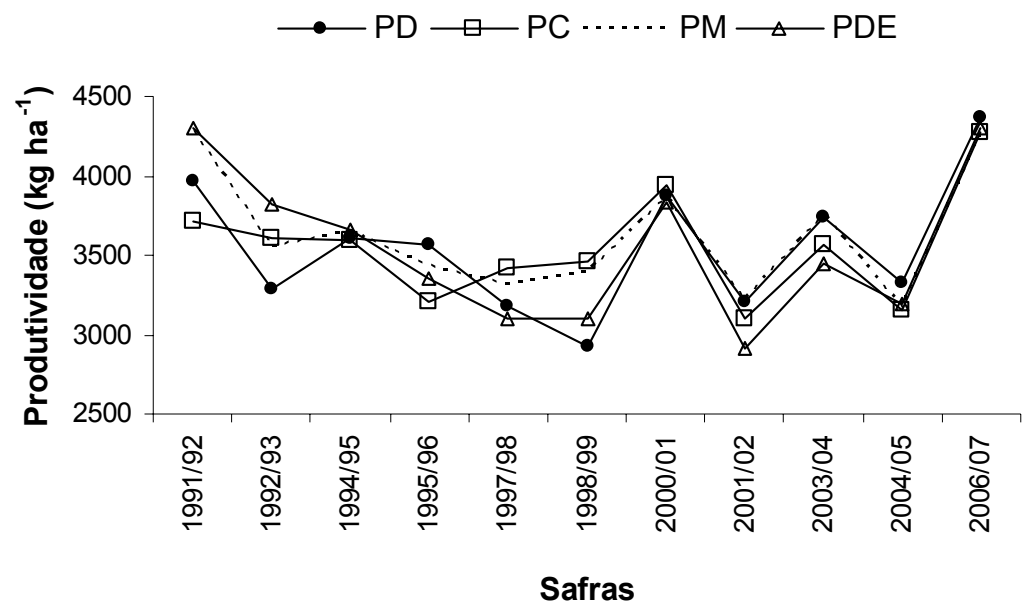

FIGURA 1 - Produtividade média da cultura da soja, nos sistemas de manejo analisados na Estação Experimental da Fundação ABC, em 11 safras: $P D$ - plantio direto; $P C$ - plantio convencional; PM - preparo mínimo; e, PDE - plantio direto com escarificação do solo a cada três anos.

A análise estatística (ANOVA) não revelou a existência de diferenças ao nível de significância de $5 \%$ entre os quatro sistemas de manejos (PD, PC, PM e PDE) estudados. Resultado semelhante também foi encontrado por Pauletti et al. (2003), na mesma área do presente estudo, em que o rendimento de grãos de milho não foi afetado pelo sistema de manejo do solo (PD, PC, PM e PDE) e de culturas ao longo dos anos. Camara \& Klein (2005), avaliando o efeito de dois mecanismos de escarificação em áreas sob o plantio direto, também verificaram que o rendimento de grãos da cultura da soja não apresentou diferença significativa entre os sistemas de manejo do solo adotados.

A Figura 2 apresenta a disposição temporal dos valores de produtividade média da cultura da soja na região de Ponta Grossa-PR, considerando os quatro sistemas de manejo, para as 11 safras analisadas. Foi utilizada a média de produtividade dos sistemas de manejo porque a análise estatística não revelou diferença significativa a $5 \%$ de erro entre elas.

Os dados apresentados na Figura 2 permitiram verificar que durante o ciclo de rotação de culturas existiu alternância entre as produtividades da cultura da soja. Observou-se para as safras de soja em anos consecutivos, que a produtividade da cultura foi sempre maior no primeiro ano em relação ao segundo, havendo redução média na produtividade de $10,31 \%$. A maior diferença ocorreu entre as safras 2000/01 e 2001/02 e ficou em 19,8\%, a menor diferença ocorreu entre as safras 1997/98 e 1998/99 e ficou em $1,1 \%$. No entanto, a variabilidade das produtividades do primeiro ano de cultivo da soja ( $C V=9,7 \%$ ), após a rotação de cultura, foi maior do que a observada no segundo ano (CV = 5,5\%).

Um cultivar em uso por vários anos o torna popular junto aos agricultores, o que propicia elevada pressão de seleção sobre os patógenos prevalecentes na região. Este fato pode levar a alterações na freqüência de genes do patógeno e resultar na vulnerabilidade desse cultivar, promovendo, conseqüentemente, "quebra" da resistência mediante o surgimento de nova raça virulenta capaz de infectar cultivares considerados resistentes em anos anteriores (Bergamin Filho et al., 1995). Assim, a seqüência de quedas de produtividade observadas no período entre as safras 1991/92 e 1998/99, pode ter ocorrido devido à utilização do mesmo cultivar - no caso específico, cultivar BR 16. 
ARAUJO, M.A. et al. Sistemas de manejo e relações hídricas do solo...

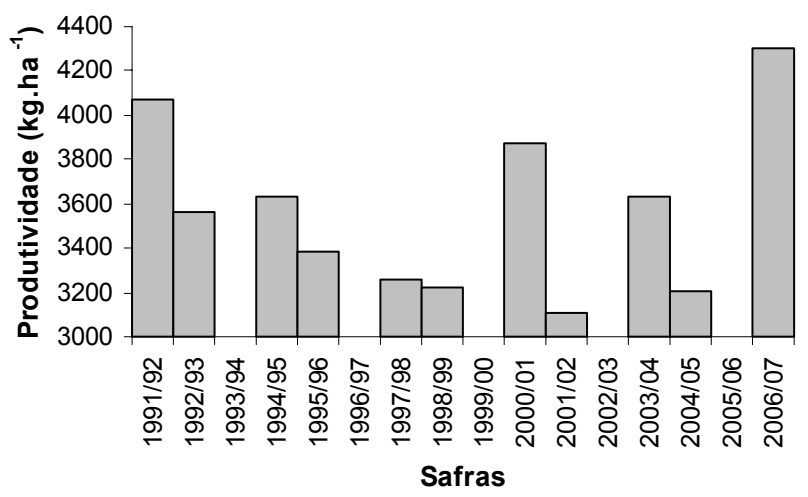

FIGURA 2 - Disposição temporal dos valores de produtividade média da cultura da soja (média dos quatro sistemas de manejo), para a região de Ponta Grossa-PR.

Além disso, a queda da produção nas safras do segundo ano após a rotação de culturas com relação às safras do primeiro pode ser explicada pelo fato de que a explosão populacional de pragas e a incidência de doenças dependem basicamente da disponibilidade de alimento e de fatores climáticos, particularmente do regime de chuvas. Como as pragas e alguns patógenos também conseguem se desenvolver em outras espécies alternativas, ou mesmo nos restos culturais sobre o solo, elas têm alimento o ano todo, facilitando a ocorrência de gerações sucessivas (Bianco, 2005). Existem patógenos, como Sclerotinia spp., que produzem estruturas de resistência capazes de sobreviver por longos períodos no solo (Bergamin Filho et al., 1995). Desta forma, quando se realiza duas safras consecutivas de uma mesma espécie, a probabilidade de ocorrência de ataques mais severos de pragas e doenças aumenta consideravelmente.

Os valores de $C A D$ para cada sistema de manejo foram determinados considerando os atributos físicos médios do solo dispostos nas Tabelas 2 e 3 e se encontram apresentados na Tabela 4. A análise de variância (ANOVA) referente aos valores de $C A D$, sob os quatro sistemas de manejo estudado não revelou efeito significativo entre os sistemas de manejo testados ao nível de $5 \%$ de significância.

Diversos autores (Veiga \& Amado, 1994; Calegari et al., 2006; Llanillo et al., 2006) afirmam que o sistema de manejo interfere em diversos atributos do solo, entre eles a condutividade hidráulica e conteúdo de água disponível, por promover, entre outros aspectos, a diminuição do tamanho de agregados e aumento temporário do espaço poroso. Contudo, as diferenças entre as CADs dos diferentes sistemas de manejo testados não se confirmaram. No entanto, é importante considerar que a estimativa dos valores de $\theta_{C C}$ e $\theta_{P M P}$ para o cálculo das CADs foram obtidas a partir de simplificações metodológicas e com valores médios para a profundidade entre 0 e $40 \mathrm{~cm}$. Devese ressaltar também que os atributos físicos considerados no modelo de pedotransferência Splintex $\left(\theta_{s u}, \rho_{s}\right.$ e granulometria) apresentaram pouca variação na área experimental (Tabela 3). No entanto os atributos $\rho_{s}$ e granulometria são utilizados na grande maioria das funções de pedotransferência (Angelotti Netto, 2007). Pavei (2005), na mesma área experimental utilizada no presente trabalho, considerando as profundidades $0-2,5 \mathrm{~cm}, 2,5-5 \mathrm{~cm}, 5-10 \mathrm{~cm}, 10-20 \mathrm{~cm}, 20-30 \mathrm{~cm}$ e $30-40 \mathrm{~cm}$, também não obteve diferença estatística entre os valores de $\rho_{s}$ para os diferentes sistemas de plantio analisados (PD, PC, PM e PDE).

Desta forma, na realização dos balanços hídricos empregou-se em cada bloco um valor único médio de $C A D$ para cada estádio fenológico da cultura, devido à inexistência de efeito significativo entre elas.

A Tabela 5 apresenta, para as 11 safras analisadas da cultura da soja na região de Ponta Grossa-PR, um resumo dos valores médios $(\mathrm{mm}$ ciclo $^{-1}$ ) dos componentes do balanço hídrico (ETo, $E T C, P, E R$, Def e Exc).

Os valores de ETc obtidos nas safras analisadas (Tabela 5) encontram-se dentro do intervalo apresentado por EMBRAPA (2006) (450 a $800 \mathrm{~mm}$ ciclo $^{-1}$ ). Os valores de $P$ nas safras foram sempre superiores aos valores de ETc. Este fato permitiu a ocorrência de excedente hídrico (Exc), contudo, não impediram a ocorrência de deficiência hídrica (Def) ao longo do ciclo da cultura em todas as safras. O menor valor de Def foi de $9,5 \mathrm{~mm}$ ciclo $^{-1}$ (safra 1994/95) e o maior valor foi de 177,9 $\mathrm{mm} \mathrm{ciclo}^{-1}$ (safra 1991/92).

Analisando-se os resultados dos balanços hídricos das 11 safras, considerando os subperíodos dos estádios fenológicos I a IV, foi possível observar que $79,5 \%$ e $85,8 \%$ dos mesmos apresentaram deficiência e excedente hídrico, respectivamente, para os quatro sistemas de manejo. Nos estádios semeadura, floração e enchimento de grãos (estádios I e III do presente trabalho), os quais são considerados os mais críticos à ocorrência de déficit hídrico, $84,1 \%$ dos subperíodos registraram sua ocorrência. 
ARAUJO, M.A. et al. Sistemas de manejo e relações hídricas do solo...

TABELA 4 - Capacidade de água disponível no solo $(C A D)$ para a cultura da soja, nos estádios de desenvolvimento I a IV, sob quatro sistemas de manejo, na Estação Experimental da Fundação ABC, Ponta Grossa-PR.

\begin{tabular}{|c|c|c|c|c|c|}
\hline \multirow{2}{*}{ Estádios fenológicos } & \multirow{2}{*}{$\begin{array}{l}\text { Profundidade } \\
\mathrm{mm}\end{array}$} & \multicolumn{4}{|c|}{ 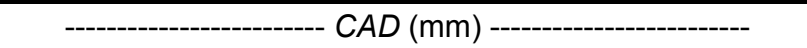 } \\
\hline & & Bloco I & Bloco II & Bloco III & Média \\
\hline \multicolumn{6}{|l|}{ Plantio Direto } \\
\hline 1 & 150 & 24,0 & 24,4 & 28,5 & 25,6 \\
\hline II & 300 & 48,0 & 48,7 & 57,0 & 51,3 \\
\hline III & 400 & 64,0 & 65,0 & 76,0 & 68,3 \\
\hline IV & 400 & 64,0 & 65,0 & 76,0 & 68,3 \\
\hline \multicolumn{6}{|l|}{ Plantio Convencional } \\
\hline 1 & 150 & 25,7 & 27,5 & 24,3 & 25,8 \\
\hline II & 300 & 51,3 & 54,9 & 48,5 & 51,6 \\
\hline III & 400 & 68,4 & 73,2 & 64,7 & 68,8 \\
\hline IV & 400 & 68,4 & 73,2 & 64,7 & 68,8 \\
\hline \multicolumn{6}{|l|}{ Preparo Mínimo } \\
\hline I & 150 & 28,1 & 16,8 & 22,6 & 22,5 \\
\hline II & 300 & 56,3 & 33,5 & 45,1 & 45,0 \\
\hline III & 400 & 75,0 & 44,7 & 60,2 & 60,0 \\
\hline IV & 400 & 75,0 & 44,7 & 60,2 & 60,0 \\
\hline \multicolumn{6}{|c|}{ Plantio Direto Escarificado } \\
\hline I & 15 & 20,5 & 20,5 & 22,7 & 21,2 \\
\hline II & 30 & 41,0 & 41,1 & 45,4 & 42,5 \\
\hline III & 40 & 54,6 & 54,8 & 60,6 & 56,6 \\
\hline IV & 40 & 54,6 & 54,8 & 60,6 & 56,6 \\
\hline
\end{tabular}

I - de S até V1/V2; II - de V2 até R1; III - de R1 até R6/R7; IV - de R7 até R9 (Costa, 1996).

TABELA 5 - Produtividade média $\left(\mathrm{kg} \mathrm{ha}^{-1}\right)$ e valores médios $\left(\mathrm{mm} \mathrm{ciclo}^{-1}\right)$ dos componentes do balanço hídrico (ETo, ETc, P, ER, Def e Exc) para as 11 safras analisadas da cultura da soja na região de Ponta Grossa-PR.

\begin{tabular}{cccccccc}
\hline \multirow{2}{*}{ Safras } & $\begin{array}{c}\text { Yr } \\
\left.\mathrm{kg} \mathrm{ha}^{-1}\right)\end{array}$ & ETo & $E T c$ & $P$ & $E R$ & Def & Exc \\
\hline $1991 / 92$ & 4068,5 & 551,4 & 642,6 & 701,0 & 464,7 & 177,9 & 189,1 \\
$1992 / 93$ & 3565,0 & 479,0 & 562,7 & 879,5 & 483,8 & 78,9 & 360,1 \\
$1994 / 95$ & 3630,0 & 486,2 & 571,0 & 1245,2 & 561,5 & 9,5 & 656,1 \\
$1995 / 96$ & 3387,5 & 482,0 & 555,8 & 925,8 & 491,4 & 64,4 & 380,2 \\
$1997 / 98$ & 3254,3 & 464,9 & 558,6 & 1205,6 & 523,3 & 35,2 & 639,9 \\
$1998 / 99$ & 3220,0 & 503,4 & 587,1 & 720,3 & 498,5 & 88,6 & 161,6 \\
$2000 / 01$ & 3873,8 & 471,0 & 548,6 & 919,9 & 524,9 & 23,7 & 388,8 \\
$2001 / 02$ & 3105,5 & 512,2 & 604,0 & 811,9 & 456,9 & 147,1 & 310,9 \\
$2003 / 04$ & 3631,0 & 448,0 & 524,0 & 616,0 & 391,9 & 132,2 & 187,3 \\
$2004 / 05$ & 3209,3 & 464,9 & 544,3 & 621,6 & 385,8 & 158,5 & 239,4 \\
$2006 / 07$ & 4297,8 & 493,1 & 583,5 & 495,0 & 428,5 & 155,1 & 83,8 \\
\hline Média & 3567,5 & 486,9 & 571,1 & 831,1 & 473,7 & 97,4 & 327,0 \\
\hline$Y r$
\end{tabular}

Yr - produtividade média; ETo - Evapotranspiração de referência; $E T C$ - evapotranspiração da cultura;

$P$ - Precipitação; ER - Evapotranspiração de real; Def - Deficiência hídrica; Exc - Excedente hídrico.

Scientia Agraria, Curitiba, v.10, n.5, p.403-412, Sept./Oct. 2009. 
ARAUJO, M.A. et al. Sistemas de manejo e relações hídricas do solo...

É válido observar que Mundstock \& Thomas (2005) afirmam que se tem verificado que os estádios I e III constituem-se em períodos críticos para a cultura da soja, sendo que a ocorrência de deficiência hídrica nesses estádios pode acarretar em perdas significativas na produtividade, por envolverem de forma direta a formação dos componentes primários do rendimento da cultura. Contudo, é importante observar que o simples registro de déficit não implica necessariamente em penalização da produtividade (Tabela 5). Desta forma, a Tabela 6 apresenta os ISNAs obtidos no presente estudo, para os quatro sistemas de manejo, de todas as safras analisadas, sendo os estádios fenológicos I (semeadura) e III (floração e enchimento de grãos) considerados os mais críticos à ocorrência de déficit hídrico.

TABELA 6 - Índice de satisfação das necessidades de água (ISNA) para a cultura da soja, considerando os estádios fenológicos I (semeadura) e III (floração e enchimento de grãos), para os quatro sistemas de manejo, nas 11 safras analisadas na região de Ponta Grossa-PR.

\begin{tabular}{ccccccccc}
\hline \multirow{2}{*}{ Safra } & \multicolumn{5}{c}{ Plantio direto } & Plan. convencional & Preparo mínimo & P. D. escarificado \\
\cline { 2 - 9 } & Estádio I & Estádio III & Estádio I & Estádio III & Estádio I & Estádio III & Estádio I & Estádio III \\
\hline $1991 / 92$ & insuficiente & bom & insuficiente & bom & insuficiente & bom & insuficiente & bom \\
$1992 / 93$ & bom & bom & bom & bom & bom & bom & bom & bom \\
$1994 / 95$ & bom & bom & bom & bom & bom & bom & bom & bom \\
$1995 / 96$ & bom & bom & bom & bom & bom & bom & bom & bom \\
$1997 / 98$ & bom & bom & bom & bom & bom & bom & bom & bom \\
$1998 / 99$ & regular & bom & regular & bom & insuficiente & bom & insuficiente & bom \\
$2000 / 01$ & bom & bom & bom & bom & bom & bom & bom & bom \\
$2001 / 02$ & insuficiente & bom & insuficiente & bom & insuficiente & bom & insuficiente & bom \\
$2003 / 04$ & bom & regular & bom & regular & bom & regular & bom & regular \\
$2004 / 05$ & bom & regular & bom & regular & bom & regular & bom & insuficiente \\
$2006 / 07$ & bom & bom & bom & bom & bom & bom & bom & bom \\
\hline
\end{tabular}

* Segundo Farias et al. (2001).

É possível verificar que os sistemas de manejo (Tabela 6) tenderam a se comportar de maneira semelhante quanto ao suprimento das necessidades hídricas da cultura da soja, o que provavelmente ocorreu devido a não existência de diferenças significativas entre as CADs (Tabela 4). As safras 1991/92, 1998/99 e 2001/02 apresentaram problemas quanto ao suprimento de água durante o estádio I. Berlato et al. (1986) e EMBRAPA (2006) afirmam que isto pode proporcionar perdas na produção final, principalmente por falhas de germinação, com conseqüente redução e desuniformidade de stand. Em relação à produtividade média das 11 safras empregando os quatro sistemas de manejo $\left(3567,5 \mathrm{~kg} \mathrm{ha}^{-1}\right)$, verificou-se que as considerações realizadas por Berlato et al. (1986) e EMBRAPA (2006) se confirmaram para as safras 1998/99 e $2001 / 02$, que produziram $347,5 \mathrm{~kg} \mathrm{ha}^{-1}$ e $462,0 \mathrm{~kg}$ $\mathrm{ha}^{-1}$ menos, respectivamente, o que representa uma diferença significativa em termos econômicos. A produtividade da safra 2001/02 (3105,5 $\left.\mathrm{kg} \mathrm{ha}^{-1}\right)$ foi a menor verificada entre todas as safras analisadas. Por outro lado, o mesmo não foi observado para a safra 1991/92, que apresentou $501 \mathrm{~kg} \mathrm{ha}^{-1}$ a mais do que a produtividade média, correspondendo a segunda maior produtividade entre as 11 analisadas.

Pauletti et al. (2003), para esta mesma área e período, atribuíram à queda na produtividade de soja do sistema de manejo plantio direto na safra 1998/99 à alta susceptibilidade do cultivar BR 16 a doenças, dando menor ênfase ao período de seca ocorrido no estádio I de desenvolvimento da cultura. Provavelmente, as doenças foram favorecidas pelo longo período chuvoso que se estendeu de dezembro de 1998 até abril de 1999, no qual praticamente não foi registrada a ocorrência de déficit hídrico. O longo período de chuvas gerou um ambiente com alta umidade relativa do ar (UR média de $80 \%$ ), temperaturas amenas (média de 21 ${ }^{\circ} \mathrm{C}$ ) e fonte de inóculo (da cobertura), valores propícios para incidência de doenças em altos graus de severidade.

As safras 2003/04 e 2004/05 apresentaram problemas quanto ao suprimento de água durante 0 estádio III. Mundstock \& Thomas (2005) consideram este o período mais sensível da planta de soja à falta de água, pois os efeitos se darão sobre aborto de flores, óvulos e legumes e, posteriormente, no tamanho, vigor e qualidade dos grãos obtidos, principalmente pela restrição da disponibilidade de fotoassimilados.

Em relação às produtividades médias das 
ARAUJO, M.A. et al. Sistemas de manejo e relações hídricas do solo...

11 safras estudadas, verificou-se que as considerações feitas por Mundstock \& Thomas (2005) se confirmaram para a safra 2004/05, apresentando $358,3 \mathrm{~kg} \mathrm{ha}^{-1}$ menos que a produtividade média, sendo a segunda menor produtividade verificada entre as safras analisadas $\left(3209,3 \mathrm{~kg} \mathrm{ha}^{-1}\right)$. No entanto, a safra 2003/04 não foi muito prejudicada, apresentando $63,5 \mathrm{~kg} \mathrm{ha}^{-1} \mathrm{a}$ mais do que a produtividade média, o que corresponde a quarta maior safra entre as safras analisadas $\left(3631,0 \mathrm{~kg} \mathrm{ha}^{-1}\right)$.

Diante dos resultados obtidos, em que não houve variação da produtividade entre os quatro sistemas de manejo: (a) Observou-se para a região a possibilidade da realização de estudos envolvendo modelos agrometeorológicos, a fim de auxiliar o planejamento de safras para região de Ponta Grossa-PR; (b) Recomenda-se à Fundação $A B C$ o aproveitamento da área experimental implantada e dos dados experimentais já coletados para desenvolver estudos visando à avaliação das causas do comportamento temporal das produtividades apresentadas pela cultura da soja, na região de Ponta Grossa-PR; (c) Um replanejamento do esquema de rotação de culturas adotado no experimento, pode ser avaliado também, buscando evitar a disposição de dois anos consecutivos com a mesma cultura em campo, bem como evitar o uso repetido de um mesmo cultivar por vários anos seguidos.

\section{CONCLUSÕES}

1) Os sistemas de manejo plantio direto, convencional, preparo mínimo e direto escarificado, implantados a mais de 11 anos em Latossolo Vermelho, textura argilosa, não proporcionaram diferença significativa nas produtividades registradas nas 11 safras estudadas, para a região de Ponta Grossa-PR;

2) A produtividade da cultura da soja, em anos consecutivos, apresentou redução média $10,31 \%$ nas safras de soja obtidas no segundo ano após a rotação da cultura, em comparação com as safras de soja obtidas no primeiro ano após a rotação.

3) Nas 11 safras analisadas, o índice de satisfação das necessidades de água (ISNA) considerando o estádio fenológico I, apresentou-se "insuficiente" em 18,2\% dos anos e "insuficiente/ regular" em $9,1 \%$ dos anos. Considerando-se o estádio III, apresentou-se "regular" em 18,2\% dos anos.

\section{AGRADECIMENTOS}

Ao CNPq, pela concessão de bolsa de mestrado; à Fundação $A B C$, pelo fornecimento dos dados de produtividade da cultura da soja; ao SIMEPAR, pela disponibilização dos dados meteorológicos da região de Ponta Grossa.

\section{REFERÊNCIAS}

1. ALLEN, R. G. et al. Crop evapotranspiration: guidelines for computing crop water requirements. Roma, 1998. (FAO Irrigation and Drainage, paper 56). Disponível em: <http://www.fao.org/docrep/X0490E/x0490e00.HTM> Acesso em: 20 set. 2007

2. ANGELOTTI NETTO, A. Estimativa da retenção de água no solo a partir do uso de equipamentos não convencionais, redes neurais artificiais e funções de pedotransferência. 2007. 167 p. Tese (Doutorado em Ciências da Engenharia Ambiental) - Escola de Engenharia de São Carlos, Universidade de São Paulo, São Carlos, 2007.

3. ARAUJO, M. A. de; SOUZA, J. L. M. de. Estimativa da evapotranspiração de referência com o método de PenmanMonteith. Versão 1.0, 2008. Disponível em: <http://www.moretti.agrarias.ufpr.br/>. Acesso em: 15 jun.2008

4. BERGAMIN FILHO, A.; KIMATI, H.; AMORIM, L. (Eds.). Manual de fitopatologia: princípios e conceitos. 3. ed. São Paulo: Agronômica Ceres, 1995, v. 1. 919 p.

5. BERLATO, M. A.; MATZENAUER, R.; BERGAMASCHI, H. Evapotranspiração máxima da soja e relações com a evapotranspiração calculada pela equação de Penman, evaporação de tanque "classe A" e radiação solar global. Agronomia Sulriograndense, v. 22, n. 2, p. 251-259, 1986.

6. BIANCO, R. Manejo de pragas do milho em plantio direto. In: INSTITUTO BIOLÓGICO DE SÃO PAULO (Org.) Encontro De Fitossanidade De Grãos. Campinas: Emopi, 2005. p. 8-17.

7. CALEGARI, A. et al. Melhoria da agregação do solo através do sistema de plantio direto. Semina:Ciências Agrárias, v. 27, n. 2, p. $147-158,2006$.

8. CAMARA, R. K.; KLEIN, V. A. Escarificação em plantio direto como técnica de conservação do solo e da água. Revista Brasileira de Ciência do Solo, v. 29, n. 5, p. 789-796, 2005.

9. COSTA, J. A. Cultura da soja. Porto Alegre: I. Manica, J. A. Costa, 1996. 233 p.

10. EMPRESA BRASILEIRA DE PESQUISA AGROPECUÁRIA (EMBRAPA). Manual de métodos de análise de solo. 2. ed. Rio de Janeiro: Embrapa CNPS, 1997, 212 p

11. EMPRESA BRASILEIRA DE PESQUISA AGROPECUÁRIA (EMBRAPA). Programa SOC - Software Científico, Versão 2.1, Embrapa Informática Agropecuária, 1990.

12. EMPRESA BRASILEIRA DE PESQUISA AGROPECUÁRIA (EMBRAPA). Tecnologias de produção de soja: Paraná 2007. Londrina: Embrapa Soja, 2006, 217 p.

13. FARIAS, J. R. B. et al. Caracterização do risco de déficit hídrico nas regiões produtoras de soja no Brasil. Revista Brasileira de Agrometeorologia, v. 9, n. 3, p. 415-421, 2001.

14. FIETZ, C. R.; URCHEI, M. A. Deficiência hídrica da cultura da soja na região de Dourados, MS. Revista Brasileira de Engenharia Agrícola e Ambiental, v. 6, n. 2, p. 262-265, 2002

15. LLANILLO, R. F. et al. Evolução de propriedades físicas do solo em função dos sistemas de manejo em culturas anuais. Semina: Ciências Agrárias, v. 27, n. 2, p. 205-220, 2006.

16. MUNDSTOCK, C. M.; THOMAS, A. L. Soja: fatores que afetam o crescimento e o rendimento de grãos. Porto Alegre: Departamento de Plantas de Lavoura da Universidade Federal do Rio Grande do Sul/ Evangraf , 2005, $31 \mathrm{p}$

17. PAULETTI, $V$. et al. Rendimento de grãos de milho e soja em uma sucessão cultural de oito anos sob diferentes sistemas de manejo de solo e de culturas. Ciência Rural, v. 33, n. 3, p. 491-495, 2003. 
ARAUJO, M.A. et al. Sistemas de manejo e relações hídricas do solo...

18. PAVEI, M. A. Decomposição de resíduos culturais e emissão de gases do efeito estufa em sistemas de manejo do solo em Ponto Grossa (PR). 2005. 114 p. Dissertação (Mestrado em Ecologia de Agroecossistemas) - Escola Superior de Agricultura "Luiz de Queiroz", Piracicaba, 2005.

19. PREVEDELLO, C. L. Programa SPLINTEX para estimar a curva de retenção de água a partir da granulometria (composição) do solo - Versão 1.0. 1999.

20. SECRETARIA DA AGRICULTURA E DO ABASTECIMENTO DO PARANÁ (SEAB). Comparativo da área e da produção de produtos selecionados, no Paraná - safras 2005/06 a 2007/08. Curitiba, 2008. Tabela. Disponível em: <http://www.pr.gov.br/seab/deral/pss.xls >. Acesso em: 02 abril 2008.

21. SOUZA, J. L. M. Programa MORETTI - Módulo balanço hídrico seqüencial (periodicidade: 1, 5, 7, 10, 15 e 30 dias), Versão 1.0, 2008. Disponível em: <http://www.moretti.agrarias.ufpr.br>. Acesso em: 15 jan. 2008.

22. SOUZA, J. L. M.; GOMES, S. Limites na utilização de um modelo de balanço hídrico decendial em função da capacidade de água disponível no solo. Acta Scientiarum Agronomy, v. 30, n. 2, p. 153-163, 2008

23. STRECK, N. A.; ALBERTO, C. M. Simulação do impacto da mudança climática sobre a água disponível do solo em agroecossistemas de trigo, soja e milho em Santa Maria, RS. Ciência Rural, v. 36, n. 2, p. 424-433, 2006.

24. THORNTHWAITE, C. W.; MATHER, J. R. The water balance. Centerton,Drexel Institute of Technology - Laboratory of Climatology, 1955. 104 p. (Publications in Climatology, v. 8, n.1)

25. VAN GENUCHTEN, M. Th. A closed-form equation for predicting the conductivity of unsaturated soils. Soil Science Society of America Journal, v. 44, n. 5, p. 892-898, 1980.

26. VEIGA, M.; AMADO, T. J. Preparo do solo. In: SANTA CATARINA. Secretaria de Estado da Agricultura e Abastecimento. Manual de uso, manejo e conservação do solo e da água: projeto de recuperação, conservação e manejo dos recursos naturais em microbacias hidrográficas. 2 ed. Florianópolis: EPAGRI, 1994. p. 165-202.

Recebido em 12/09/2008

Aceito em 31/05/2009 